\title{
Efeito da inclusão de polpa cítrica peletizada na confecção de silagem de capim-elefante (Pennisetum purpureum, Schum.) ${ }^{1}$
}

\author{
Paulo Henrique Mazza Rodrigues ${ }^{2,3}$, José Ricardo Lobo ${ }^{4}$, Estela Jorge Alves da Silva ${ }^{4}$, Luis \\ Felipe Onofre Borges ${ }^{4}$, Paula Marques Meyer ${ }^{5}$, João José Assumpção de Abreu Demarchi ${ }^{6}$
}

${ }_{1}^{1}$ Pesquisa financiada pela Fundação de Amparo à Pesquisa do Estado de São Paulo (FAPESP).

2 Depto de Nutrição e Produção Animal - FMVZ/USP, C.P. 23 - CEP:13630-000 - Pirassununga, SP.

${ }^{3}$ Bolsista em Produtividade em Pesquisa pelo CNPq.

${ }^{4}$ Mestrando do Departamento de Nutrição e Produção Animal - FMVZ/USP.

5 Instituto Brasileiro de Geografia e Estatística - IBGE.

${ }^{6}$ Agência Paulista de Tecnologia dos Agronegócios - APTA.

RESUMO - Objetivou-se com esta pesquisa avaliar os efeitos da idade de corte do capim-elefante cv. Napier (Pennisetum purpureum Schum.) e da inclusão da polpa sobre a qualidade fermentativa e a estabilidade aeróbia da silagem, além de elaborar um índice de recomendação da inclusão de polpa cítrica, em função do teor de umidade do capim, para reduzir os custos com esta tecnologia. Foram confeccionados silos de laboratório (capacidade de 6 litros) e testados 20 tratamentos (quatro repetições), correspondentes a cinco idades de crescimento do capim (40,60,80, 100 ou 120 dias após corte de nivelamento) e quatro níveis de inclusão de polpa cítrica peletizada ( $0,3,6$ ou 9\%, com base na matéria natural do capim), em arranjo fatorial 5 x 4. Houve efeito da interação idade de corte $\times$ nível de polpa sobre as concentrações de ácidos acético, propiônico, butírico e lático, a relação lático/acético, o pH, o nitrogênio amoniacal e a temperatura máxima, mas não para a concentração de álcool, a digestibilidade in vitro da MS, o tempo para atingir a temperatura máxima, a taxa para elevação da temperatura e o tempo para elevação da temperatura em $2^{\circ} \mathrm{C}$. A inclusão de polpa melhorou o perfil fermentativo das silagens, com efeito mais pronunciado em silagens produzidas com capins mais novos. Com base no teor de ácido acético e em derivações da equação de superfície gerada, foi possível obter a recomendação de inclusão de $0,7 \%$ de polpa cítrica (com base na matéria natural do capim) para cada unidade percentual de MS que o capim possuir abaixo de 32. Portanto, o nível ótimo de inclusão de polpa que otimiza a qualidade da silagem é igual a (32-MS) x 0,7 .

Palavras-chave: ácidos orgânicos, fermentação, matéria seca

\section{Effect of pelleted citrus pulp inclusion on elephantgrass (Pennisetum purpureum, Schum.) ensiling}

\begin{abstract}
The objectives of this trial were to evaluate the effects of regrowth age of elephantgrass (Pennisetum purpureum Schum. cv. Napier), and citrus pulp addition on the fermentation pattern and aerobic stability of their silage. In addition to that, this research also aimed to create a recommendation index of citrus pulp addition taking into account the moisture concentration of the grass, in order to decrease costs of technology adoption. Laboratory silos (6 L-capacity each) were used and 20 treatments were tested, corresponding to 5 different grass regrowth ages $(40,60,80,100$, or 120 days after harvesting) and four levels of citrus pulp pellets $(0,3,6$, or $9 \%$, based on grass fresh matter) in a factorial arrangement $5 \times 4$, with four replicates. Regrowth age and citrus pulp addition level interacted for acetic, propionic, butyric, and lactic acid concentrations, lactic/acetic acid ratio, $\mathrm{pH}$, ammoniacal nitrogen, and maximum temperature, but did not for alcohol concentration, in vitro DM digestibility, time to achieve the maximum temperature, rate for increasing temperature, and time for increasing temperature in $2^{\circ} \mathrm{C}$. In general, the addition of citrus pulp improved fermentation pattern of silages, with greater effect when silages were produced with high moisture grasses. Based on acetic acid concentration and using derivations from the surface equation, it was possible to recommend the addition of $0.7 \%$ of citrus pulp (based on grass fresh matter) for each percentage unit of grass DM lower than $32 \%$. Therefore, the optimum addition level of citrus pulp which optimizes silage quality is equal to $(32-\mathrm{DM}) \times 0.7$.
\end{abstract}

Key Words: dry matter, fermentative quality, organic acids 


\section{Introdução}

No inverno, a pequena disponibilidade de forragens e seu baixo valor nutritivo são os principais fatores responsáveis pela acentuada queda na produção de carne e de leite, resultando em baixa taxa de desfrute (Andrade, 1999). As gramíneas forrageiras tropicais, com o avanço do crescimento vegetativo, aumentam sua produção por área, tendo, em contrapartida, seu valor nutritivo diminuído. Nestas condições, conseqüentemente, o produto obtido no processo de ensilagem também é de baixo valor nutritivo. Por outro lado, quando estas são ensiladas em estádio de desenvolvimento mais novo, três de suas características podem interferir no processo da ensilagem: alto teor de umidade, alta capacidade tampão e baixos teores de carboidratos solúveis. Estes fatores influem negativamente sobre o processo fermentativo, impedindo o rápido decréscimo do $\mathrm{pH}$ a níveis adequados e permitindo fermentações secundárias indesejáveis, o que prejudica a qualidade do produto preservado (Peres, 1997).

Para contornar este problema, pode-se optar pela adição de materiais absorventes com alto teor de MS, de forma a reduzir a umidade do material ensilado. Destaca-se a polpa de citros, um subproduto da extração do suco de laranja que possui alta capacidade de absorção de água, alto teor de carboidratos solúveis, alto valor nutritivo e boa aceitabilidade pelos animais, entre outras características, constituindo-se um suplemento ideal para viabilização da ensilagem de capim-elefante (Faria et al., 1972).

Este trabalho foi conduzido com o objetivo de avaliar os possíveis benefícios da inclusão de diferentes níveis de polpa cítrica na ensilagem de capim-elefante em diferentes estádios vegetativos. Adicionalmente, objetivou-se também elaborar um índice de recomendação da inclusão de polpa cítrica em função do teor de umidade do capim.

\section{Material e Métodos}

O experimento foi conduzido nas dependências do Departamento de Nutrição e Produção Animal da Faculdade de Medicina Veterinária e Zootecnia da Universidade de São Paulo (Campus de Pirassununga-SP).

Foram confeccionadas silagens de capim-elefante (Pennisetum purpureum Schum., cultivar Napier). Após a colheita manual, a planta foi picada (Picadora - marca Nogueira, modelo EM-9F3B) em fragmentos de tamanho teórico médio de $1,32 \mathrm{~cm}$. A avaliação do tamanho médio de partículas foi feita segundo metodologia das peneiras do "PennState Particle Size Separator", proposta por Lammers et al. (1996), adaptado por Heinrichs \& Kononoff (2002). Foram utilizados 80 silos experimentais confeccionados a partir de baldes plástico com $252 \mathrm{~mm}$ de altura e $245 \mathrm{~mm}$ de diâmetro $\left(0,06174 \mathrm{~m}^{3}\right)$. Adotou-se arranjo fatorial de tratamentos 5 x 4, correspondendo a 20 tratamentos formados pela combinação de cinco idades de corte e quatro porcentagens de adição de polpa cítrica. As idades de crescimento para o corte do capim foram 40,60,80,100 ou 120 dias e as porcentagens de polpa adicionadas, $0,3,6$ ou $9 \%$ em base de matéria fresca da polpa e do capim. Os silos foram fechados e imediatamente pesados, sendo, então, mantidos em local abrigado e abertos somente após 145 dias de armazenamento.

Antes da abertura, os silos foram novamente pesados para posterior determinação das perdas de MS. Os cálculos das perdas por fermentação foram realizados por meio da diferença entre os pesos das massas obtidos no enchimento e na abertura dos silos, multiplicados pelos respectivos teores de MS. Finalmente, as perdas foram transformadas em porcentagem da massa inicial. Uma vez abertos, as massas retiradas de cada silo foram homogeneizadas, sendo uma parcela separada para determinação de MS a 65 e $105^{\circ} \mathrm{C}$ em estufa com ventilação forçada; de PB, segundo AOAC (1980); e dos componentes da parede celular (FDN, FDA e lignina em detergente ácido) segundo Van Soest et al. (1991). Para a análise de FDN, foi utilizada a $\alpha$-amilase e para as frações FDA e lignina em detergente ácido utilizou-se o método seqüencial, segundo Van Soest et al. (1991). As determinações de carboidratos solúveis (CHOs) foram feitas segundo Johnson et al. (1966) e de amido, segundo técnica proposta por Pereira \& Rossi (1995), modificada para prévia extração dos CHOs, segundo Hendrix (1993). O teor de nitrogênio insolúvel em detergente ácido (NIDA) e o poder tampão foram analisados segundo recomendações de Van Soest \& Robertson (1985) e Playne \& McDonald (1966), respectivamente.

Uma fração da amostra foi congelada imediatamente para futura contraprova e outra foi colocada em prensa manual para extração do suco. Imediatamente após a prensagem do material, $50 \mathrm{~mL}$ de suco de silagem foram utilizados para determinação do pH (medição em potenciômetro). Parte do suco foi fixada $(0,2 \mathrm{~mL}$ de ácido fórmico para cada 1,0 $\mathrm{mL}$ de suco de silagem) e congelada para posterior determinação dos ácidos orgânicos (lático, acético, propiônico e butírico) e etanol, por meio de cromatografia gasosa (Erwin et al., 1961). Outra parte do suco foi ainda fixada $(1,0 \mathrm{~mL}$ de ácido sulfúrico $1 \mathrm{~N}$ para cada 2,0 mL de suco de silagem) e congelada para posterior determinação do nitrogênio amoniacal por espectrofotometria 
(Foldager, 1977). A digestibilidade in vitro da MS (DIVMS) foi determinada conforme recomendações propostas por Tilley \& Terry (1963).

Para determinação da estabilidade aeróbia da silagem, aproximadamente $2,0 \mathrm{~kg}$ de massa úmida foram retirados de cada balde, transferidos para caixas de isopor (12 L) e armazenadas em local coberto com temperatura controlada $\left(25^{\circ} \mathrm{C}\right)$. As temperaturas das silagens foram obtidas a cada uma hora, durante sete dias, por meio de um Sistema de Monitoração e Aquisição de Dados (SIMAD) composto por sensores de temperatura, módulos de aquisição de dados, conversor de rede e software para Monitoramento, Aquisição e Controle de Variáveis Ambientais (MACVA), versão 1.2 de fabricação da AUTSENS (Indústria e Comércio de Equipamentos Eletrônicos). Ensaios prévios conduzidos no laboratório (dados não publicados), com 21 dias de monitoramento da temperatura, mostraram que sete dias de observação foram suficientes para não se perder o registro do pico de máxima temperatura. A estabilidade aeróbia foi calculada como uma taxa de elevação de temperatura, usando o máximo da temperatura observada, dividida pelo tempo necessário para alcançar a máxima temperatura (Ruppel et al., 1995). A estabilidade também foi calculada contando-se o tempo necessário para elevar a temperatura da massa em $2{ }^{\circ} \mathrm{C}$, segundo Kung \& Ranjit (2001). Adicionalmente avaliaram-se as temperaturas máximas alcançadas (em escala Celsius) e o tempo necessário para alcançar estas máximas (em horas).

Os dados foram submetidos à análise de regressão polinomial, pelo procedimento General Linear Model (GLM) (SAS, 1985), decompondo os efeitos em lineares e quadráticos (efeitos linear para ambos os fatores, linear para a idade de corte e quadrático para o nível de polpa, quadrático para a idade de corte e o nível de polpa e quadrático para ambos os fatores). Foi possível obter a equação de superfície gerada pelo procedimento de regressão múltipla (PROC REG), pela metodologia dos quadrados mínimos, na qual as variáveis independentes são representadas pela idade de corte e pelo nível de polpa. Adicionalmente, com a derivação da curva de superfície foi possível obter recomendações do nível mais indicado de inclusão de polpa para cada idade de corte, com base nos diferentes parâmetros estudados. Adotou-se nível de significância de 5\% para todos os testes realizados.

\section{Resultados e Discussão}

Os teores das diversas frações de nutrientes obtidos para o capim-elefante (Tabela 1) são compatíveis ao do capim cortado aos 40,60, 80, 100 e 120 dias de idade e os dados de polpa cítrica, semelhantes aos relatados na literatura (Braga et al., 2001; Queiroz Filho et al., 2000).

Houve efeito da interação idade de corte $\times$ nível de polpa cítrica sobre os teores de MS, de modo que, à medida que aumentou a idade de corte da forrageira, elevou-se linearmente o teor de MS da silagem (Tabela 2). A inclusão de polpa também aumentou, de forma quadrática, o teor de MS da silagem - efeito ligeiramente mais pronunciado em capins cortados mais novos. Braga et al. (2001), analisando a composição químico-bromatológica das silagens de capim-elefante em cinco idades de corte $(56,70,84,98$ ou 112 dias), também observaram efeito da idade sobre o teor de MS. Rodrigues et al. (2005) observaram que, à medida que aumentou o nível de inclusão de polpa cítrica $(0 ; 2,5 ; 5,0 ; 7,5$; $10,0 ; 12 ; 5$ ou $15,0 \%)$ na massa ensilada de capim-elefante, elevou-se linearmente o teor de MS das silagens. Os valores

Tabela 1 - Composição bromatológica do capim-elefante (idade de corte) e polpa cítrica utilizados para confecção das silagens ${ }^{1}$ Table 1 - Chemical composition of elephantgrass (cutting age) and citrus pulp used to produce the silages

\begin{tabular}{lccccccccc}
\hline Item & MS & PB & FDN & FDA & Lig. & Amido & CHO & NIDA & DIVMS \\
CE (dias) & $D M$ & $C P$ & NDF & ADF & Lig. & Starch & WSC & ADIN \\
$E G$ (days) & & & & & & & & \\
\hline 40 & 11,61 & 16,99 & 64,68 & 35,70 & 3,89 & 0,00 & 1,24 & 0,78 \\
60 & 16,44 & 10,80 & 72,05 & 36,90 & 4,49 & 0,07 & 1,36 & 1,07 \\
80 & 19,69 & 8,06 & 71,25 & 37,94 & 5,25 & 0,07 & 1,29 & 0,87 \\
100 & 22,32 & 9,47 & 70,81 & 34,80 & 4,94 & 0,24 & 0,96 & 0,77 \\
120 & 25,64 & 7,72 & 73,60 & 39,83 & 6,71 & 1,11 & 1,26 & 0,95 \\
Polpa cítrica & 89,92 & 6,88 & 27,80 & 12,31 & 3,75 & 1,93 & 22,39 & 0,53 \\
Citrus pulp & & & & & & & & & \\
\hline
\end{tabular}

CE - capim-elefante; MS - matéria seca total (\%); PB - proteína bruta (\%MS); FDN - fibra em detergente neutro (\%MS); FDA - fibra em detergente ácido (\%MS); Lig. - lignina em detergente ácido (\%MS); Amido (\%MS); CHO - carboidratos solúveis (\%MS); NIDA - nitrogênio insolúvel em detergente ácido (\% do nitrogênio total); DIVMS - digestibilidade in vitro da MS (\%MS).

EG: elephantgrass; DM: dry matter (\%); CP: crude protein (DM\%); NDF: neutral detergent fiber (DM\%); ADF: acid detergent fiber (DM\%); Lig.: lignin (DM\%); Starch (\%DM); WSC: watersoluble carbohydrate (DM\%); ADIN: acid detergent insoluble nitrogen (\% of total N); IVDMD: in vitro DM digestibility (DM\%). 
Tabela 2 - Composição química das silagens ${ }^{1}$

Table 2 - Chemical composition of silages

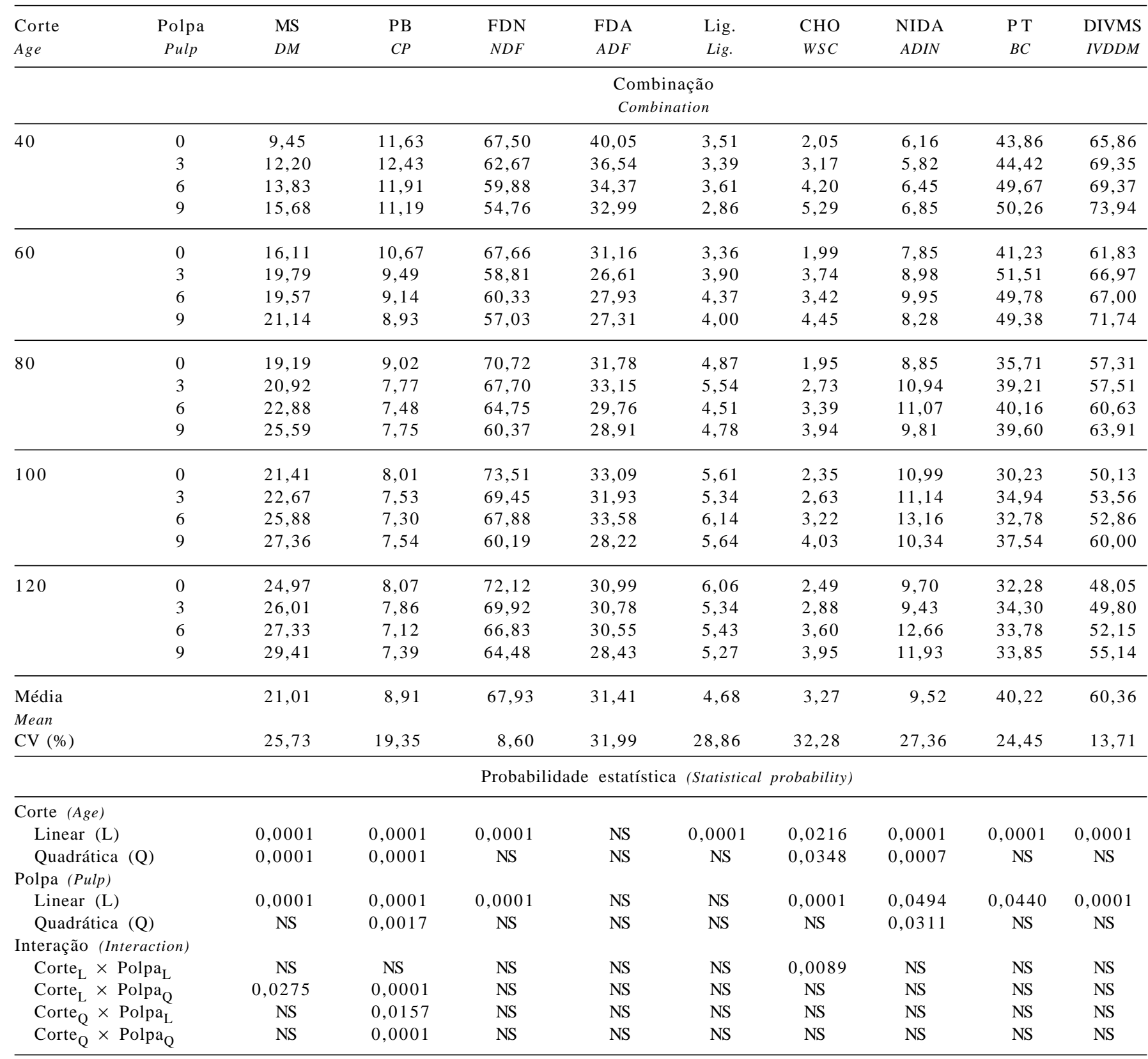

${ }^{1}$ MS - matéria seca total (\%); PB - proteína bruta (\%MS); FDN - fibra em detergente neutro (\%MS); FDA - fibra em detergente ácido (\%MS); Lig. - lignina (\%MS); CHO - carboidratos solúveis (\%MS); NIDA - nitrogênio insolúvel em detergente ácido (\% do nitrogênio total); PT - poder tampão (meqHCl/100gMS); DIVMS = digestibilidade in vitro da MS (\%MS); CV: coeficiente de variação (\%); NS: não-significativo.

1 DM:dry matter (\%); CP: crude protein (DM\%); NDF: neutral detergent fiber (DM\%); ADF: acid detergent fiber (DM\%); Lig.: lignin (DM\%); WSC: water-soluble carbohydrate (DM\%); ADIN: acid detergent insoluble nitrogen (\% of total N); BC: buffer capacity (meqHCI/100gDM); IVDMD: in vitro DM digestibility (DM\%); CV: coefficient of variation (\%); NS: not significant.

de MS obtidos para a silagem deste experimento estão abaixo dos teores de 30 a $40 \%$ citados por Silveira et al. (1980), como necessários para garantir a produção de silagens de boa qualidade.

Observou-se efeito de interação idade de corte $\times$ nível de polpa cítrica sobre os teores de $\mathrm{PB}$, sendo o efeito quadrático para ambos os fatores estudados. Os valores absolutos obtidos para este parâmetro foram considerados bons (7,12 a 12,43\%), compatíveis com o nível mínimo de PB
(7\%), citado por Silva \& Leão (1979) como necessário ao bom funcionamento ruminal e, conseqüentemente, ao bom desempenho animal. Rodrigues et al. (2005) também observaram efeito quadrático (inicialmente crescente e, após, decrescente) para proteína com a adição de polpa cítrica. Evangelista et al. (2000), trabalhando com silagem de gramínea estrela roxa, concluíram que os maiores valores de PB foram observados nas silagens sem polpa (teor médio de $13,5 \%$ ) em relação àquelas acrescidas de polpa cítrica (teor 
médio de 12,8\%). Deve-se atentar ao fato de a adição de polpa cítrica aumentar os teores de PB da silagem, quando administrada em pequenas quantidades, e, após, diminui-los. Por ter menor concentração de PB que o capim, espera-se que qualquer mistura entre polpa e capim possua menor teor de PB, em relação ao capim ou sua silagem quando tomados isoladamente. Entretanto, isto não ocorre em função do efeito positivo da adição de polpa cítrica sobre o processo fermentativo, diminuindo as perdas de compostos nitrogenados por volatilização. Espera-se que esse fenômeno seja mais evidente com pequenas adições de polpa, quando o efeito de diluição é menor.

Não se observou efeito da interação idade de corte $\times$ nível de polpa cítrica sobre os teores de FDN das silagens, que foram reduzidos linearmente à medida que se elevou a adição de polpa cítrica, provavelmente em decorrência do baixo teor de FDN deste aditivo (28\%), em comparação ao observado para o capim-elefante (acima de 64\%).

Quanto ao estádio vegetativo, houve aumento linear dos teores de FDN com o avanço da idade de corte, variando de $67,5 \%$ para o capim aos 40 dias a $72,1 \%$ para o capim aos 120 dias de crescimento não-adicionado de polpa. Estes resultados corroboram aqueles encontrados por Queiroz Filho et al. (2000). Não houve efeito da idade de corte ou do nível de polpa cítrica sobre os valores da variável FDA. Crestana et al. (2001) verificaram tendência de redução nos teores de FDA de $42,5 \%$ ( $0 \%$ de polpa) para $39,7 \%$ ( $5 \%$ de polpa) e 39,0\% (10\% de polpa) com a adição de polpa cítrica. Não houve efeito de interação idade de corte $\times$ nível de polpa cítrica para a variável lignina. Apenas a idade de corte apresentou efeito linear significativo para os teores de lignina, que se elevaram com o avanço do estádio vegetativo da forrageira, corroborando os valores obtidos por Deschamps (1999). Crestana et al. (2001), por sua vez, observaram tendência na redução do teor de lignina nos tratamentos com inclusão de polpa, como efeito da diluição desse composto na silagem de capim-tanzânia (Panicum maximum cv. Tanzânia).

Houve efeito de interação idade de corte $\times$ nível de polpa cítrica sobre a concentração de carboidratos solúveis, sendo linear para ambos os fatores e constatando-se aumento considerável com a elevação na porcentagem de aditivo somada à forrageira. A presença de polpa cítrica aumentou os teores de carboidratos solúveis, o que era esperado, uma vez que o aditivo é rico neste nutriente e, apesar da baixa concentração de carboidratos nos tratamentos estudados, proporcionou silagem de qualidade satisfatória. Os resultados estão de acordo com o observado por Rodrigues et al. (2005), em silagens de capim-elefante, nas quais a adição de polpa cítrica com elevado teor de $\mathrm{CHO}$ (25,96\% da MS) propiciou aumento linear da concentração deste nutriente na massa ensilada.

Embora não tenha sido observado efeito da interação idade de corte $\times$ nível de inclusão de polpa cítrica sobre o NIDA, separadamente ambas apresentaram efeito quadrático. Rodrigues et al. (2005) notaram comportamento quadrático dos teores de NIDA com a adição de polpa cítrica, sendo os menores teores alcançados com 4,7\% de inclusão de polpa. Por outro lado, Reis et al. (2003) não observaram diferenças nos conteúdos de nitrogênio ligado à fração fibrosa da silagem de gramínea produzida com diferentes conteúdos de umidade.

Não houve efeito da interação idade de corte do capim $\times$ nível de inclusão de polpa, apresentando apenas efeito linear para ambas em relação ao PT. Observou-se que houve diminuição do PT com o avanço do estádio vegetativo da forrageira e aumento do PT com o incremento dos níveis de polpa cítrica. Estes resultados corroboram os obtidos por Evangelista et al. (2001) e refletem a presença de ácidos orgânicos, especialmente os ácidos acético e lático, da silagem. O poder tampão das forrageiras tropicais é relativamente alto, em função da quantidade de ácidos orgânicos presentes nas forragens. Estes ácidos agem impedindo a queda do $\mathrm{pH}$ da massa ensilada (Vilela, 2004).

A idade de corte e o nível de polpa cítrica apresentaram resposta linear em relação à DIVMS, sem que fosse observada interação entre elas. Houve aumento linear crescente na DIVMS com o incremento do nível da polpa e diminuição da idade do capim. Estes resultados parecem compatíveis com outros trabalhos encontrados na literatura, que têm demonstrado diminuição na digestibilidade da MS com o avanço da maturidade fisiológica da forrageira (Campos et al., 2002) e aumento na DIVMS com a aditivação com polpa (Peres, 1997).

Não houve efeito da interação idade de corte $\times$ nível de polpa cítrica sobre a concentração de álcool, observando-se que a idade de corte acarretou resposta quadrática e o nível de polpa cítrica, resposta linear, aumentando os teores com a elevação nos níveis do aditivo (Tabela 3). Os efeitos encontrados neste experimento corroboram os obtidos por Rodrigues et al. (2005), que, em estudo com níveis crescentes de polpa cítrica sobre a qualidade fermentativa da silagem de capim-elefante, constataram que a concentração de etanol foi significativamente aumentada pela inclusão de polpa.

Observou-se efeito da interação idade de corte do capim $\times$ nível de inclusão de polpa cítrica sobre a concentração de ácido acético (\% da MS); linear para a idade do capim, diminuindo com o avanço da idade, e curvilinear para 
Tabela 3 - Características fermentativas das silagens ${ }^{1}$

Table 3 - Fermentation characteristics of silages

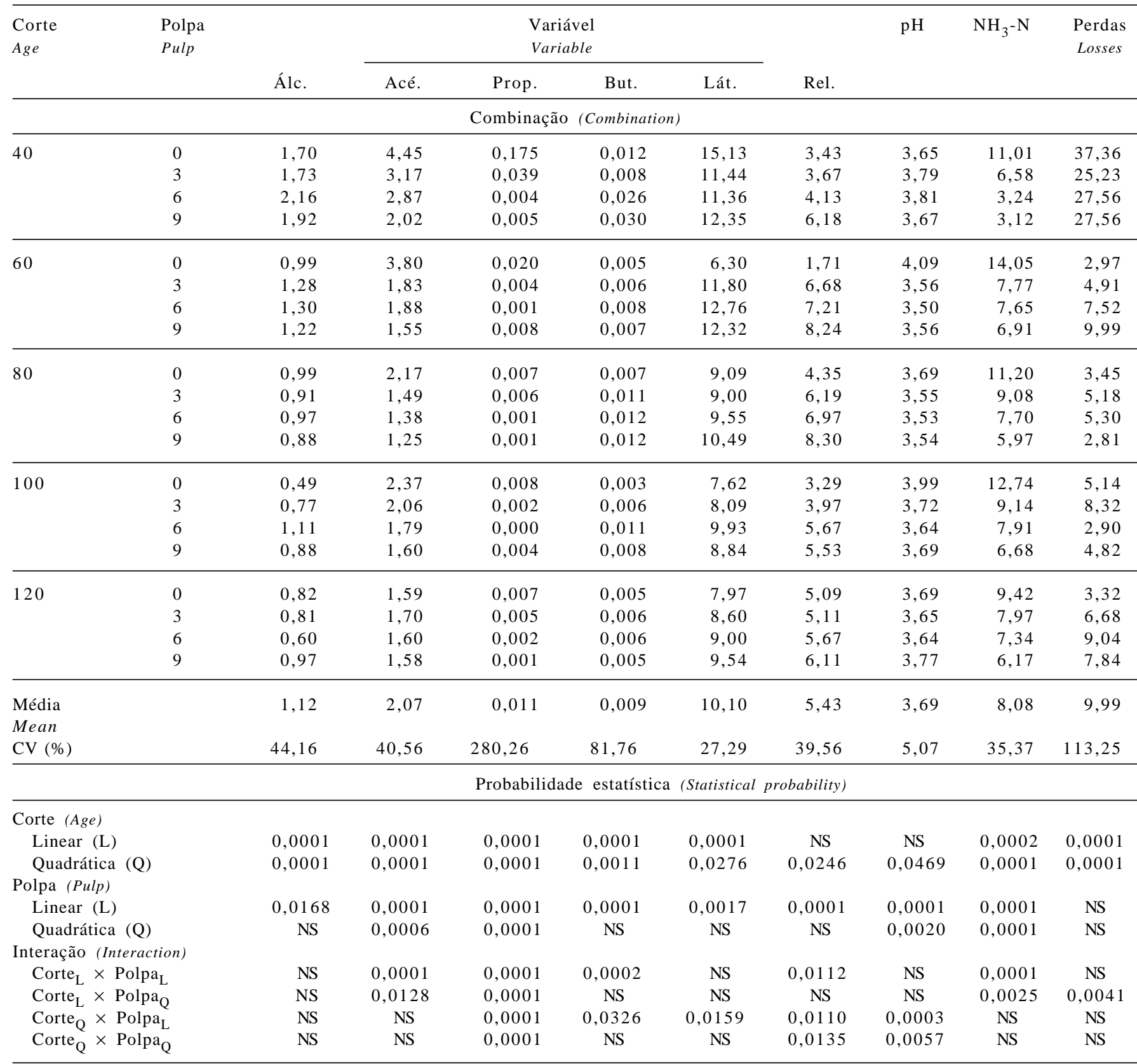

${ }^{1}$ Álc. - álcool (\%MS); Ace. - acético (\%MS); Prop. - propiônico (\%MS): But. - butírico (\%MS); Lát. - lático (\%MS); Rel. - relação lático/acético; $\mathrm{N}-\mathrm{NH} \mathrm{H}_{3}$ - nitrogênio amoniacal (\% do N total); Perdas - perdas de MS (\%); CV - coeficiente de variação; NS - não-significativo.

${ }^{1}$ Alc.- alcohol (DM\%); Ace. - acetic (DM\%); Prop. - propionic (DM\%); But. - butyric (DM\%); Lact. - lactic (\%DM); Rel. - lactic/acetic ratio; $N H_{3}-\mathrm{N}$ - amonniacal nitrogen (\% of total N); CV - coefficient of variation (\%); NS - not significant.

o nível de polpa (Figura 1). Os resultados desta pesquisa corroboram os obtidos por Rodrigues et al. (2005), que encontraram resposta quadrática para a concentração de ácido acético com a adição de polpa cítrica à silagem de capim-elefante, obtendo-se a menor concentração para o ácido acético no nível de 7,8\%.

A concentração de ácido acético foi escolhida para a criação de um índice de recomendação de inclusão de polpa cítrica, por constituir importante ácido no processo fermentativo da silagem. Além disso, os efeitos quadrático para polpa e linear para idade de corte de capim permitiram a determinação do ponto ótimo de inclusão de polpa nas diferentes idades de corte de capim. Observou-se também que os valores de ácido acético ficaram acima ou abaixo dos recomendados por Mahanna (1997), comprovando a eficácia dos tratamentos em melhorar o perfil deste ácido orgânico.

Com base na equação de superfície obtida, foi possível calcular, pela derivação matemática, o nível ótimo de inclusão de polpa cítrica peletizada (NOP) que resultaria na menor 
concentração de ácido acético da silagem para cada idade de corte do capim (Figura 2). Quando esses dados foram regredidos, não em função da idade de corte, mas do teor de umidade do capim (UC) associado para cada idade de corte, obteve-se a seguinte equação de regressão: NOP = $-48,591+0,717 \mathrm{UC}\left(\mathrm{R}^{2}=0,9977\right)$. Isso significa que, para se obter a mínima concentração de ácido acético na silagem, deve-se adicionar $0,717 \%$ de polpa cítrica (com base na matéria original do capim) para cada unidade percentual de umidade do capim. Portanto, não se recomenda adicionar polpa cítrica $(\mathrm{NOP}=0)$ quando o capim possuir menos do que $67,77 \%$ de umidade ( $\mathrm{se} \mathrm{NOP}=0$, então $0=-48,591$ $+0,717 \mathrm{UC} \Rightarrow \mathrm{UC}=67,77 \%$ ), o que corresponde a $32,23 \%$ de MS.

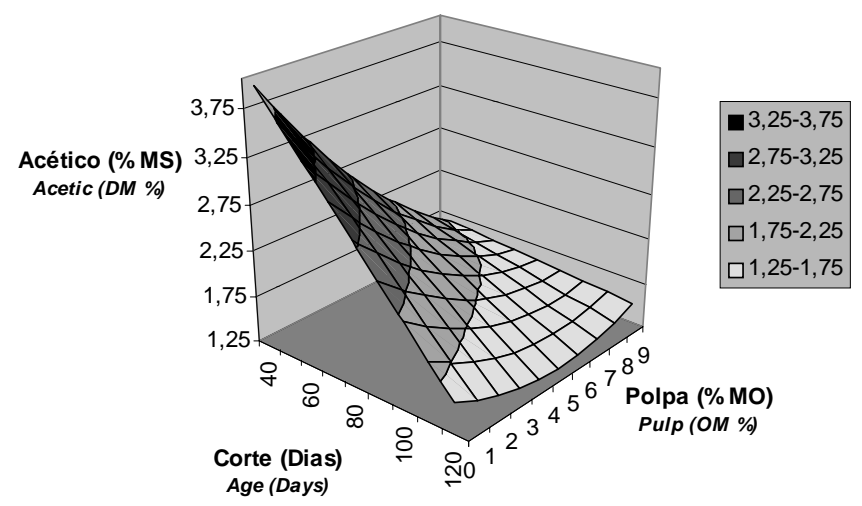

Figura 1 - Efeito da idade de corte (Corte) e do nível de polpa cítrica (Polpa) sobre a concentração de ácido acético (\% da MS) em silagem de capim-elefante.

Figure 1 - Effect of cutting age and addition of citrus pulp (Pulp) on acetic acid concentration (DM \%) of elephantgrass silage.

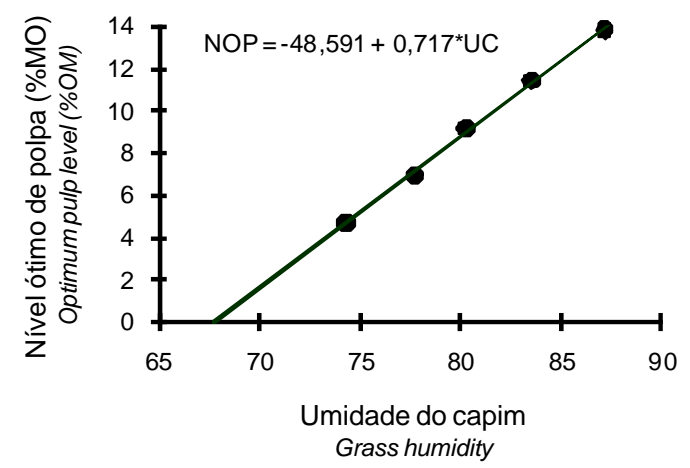

Figura 2 - Relação entre o nível ótimo de polpa cítrica peletizada (\% da matéria original do capim) e o teor de umidade do capim-elefante (em \%).

Figure 2 - Relationship between optimum level of pelleted citrus pulp - NOP (as original matter \% of grass) and grass humidity UC (\%).
Simplificando a equação, é recomendável adicionar aproximadamente $0,7 \%$ de polpa cítrica peletizada para cada unidade percentual de MS que o capim possuir abaixo de $32,0 \%$, ou seja, NOP = (32-MS) x 0,7. Exemplificando, capins com 15,20 ou $25 \%$ de MS devem receber quantidades de polpa cítrica peletizada iguais a $11,9 \%$ [(32-15) x 0,7], 8,4\% [(32-20) x 0,7$]$ ou $4,9 \%$ [(32-25) x 0,7], respectivamente, da matéria original do capim. Neste trabalho, optou-se por apresentar o nível de inclusão de polpa cítrica peletizada em função da matéria original do capim, de modo a facilitar o trabalho do técnico de campo e evitar erros nos cálculos. Deve-se considerar também que esse nível de inclusão de polpa é válido quando este subproduto apresentar aproximadamente $90 \%$ de MS, valor de MS mais adotado nas pesquisas. Teores de MS da polpa diferentes de $90 \%$ exigirão correções na recomendação do nível de inclusão de polpa.

Houve efeito da interação $\times$ idade de corte e nível de polpa cítrica sobre a concentração de ácido propiônico, sendo que ambos os efeitos apresentaram resposta quadrática para esta variável. Os valores de ácido propiônico obtidos no presente experimento foram baixos (Média de 0,01\%). Ferrari Jr. \& Lavezzo (2001), estudando os efeitos do emurchecimento ou da adição de raspa de mandioca à silagem do capim-elefante (Pennisetum purpureum, Schum.) sobre a concentração de ácido propiônico, também observaram baixas concentrações deste ácido na silagem desta gramínea.

Constatou-se efeito da interação idade de corte $\times$ nível de polpa cítrica sobre a concentração de ácido butírico, sendo que a idade de corte apresentou resposta quadrática e o nível de polpa cítrica, resposta linear, aumentando a produção do ácido butírico com o incremento do nível de polpa cítrica. Porém, com relação ao ácido butírico, o aumento causado pela polpa foi mais pronunciado com a redução da idade de corte do capim. Os dados obtidos neste trabalho diferem daqueles obtidos por Faria et al. (1972), os quais observaram que a adição de polpa cítrica seca praticamente eliminou o desenvolvimento de fermentações butíricas.

Observou-se efeito da interação idade de corte $\times$ nível de polpa cítrica sobre a concentração de ácido lático, sendo que a idade de corte apresentou resposta quadrática e o nível de polpa cítrica, resposta linear, elevando a produção do ácido lático com o aumento do nível do aditivo. Reis et al. (2003) também encontraram valores maiores de ácido lático para silagens de capim-Tifton 85 adicionados de polpa cítrica, em relação às silagens com pré-emurchecimento e controle. Por outro lado, os resul- 
tados desta pesquisa diferem dos obtidos por Rodrigues et al. (2005), que observaram efeito quadrático da adição de polpa cítrica sobre os teores de ácido lático e concluíram que a produção máxima de ácido lático foi obtida com 5,8\% de inclusão de polpa cítrica.

Houve efeito da interação idade de corte $\times$ nível de polpa cítrica sobre a relação lático/acético, sendo que ambos apresentaram resposta quadrática para esta variável. Rodrigues et al. (2004), trabalhando com silagens de alfafa tratadas com polpa cítrica, também constataram que a adição de polpa foi capaz de elevar a relação lático/acético de 0,3 para 3,0. Este valor (relação lático/acético igual a 3,0) foi considerado como o mínimo para caracterização de uma silagem onde ocorreu fermentação desejável. Neste estudo, as silagens sem a adição de polpa já apresentavam valores adequados de relação lático/acético (excetuando idade de corte igual a 60 dias), embora a adição desse subproduto melhorasse ainda mais esse parâmetro.

Houve também efeito de interação idade de corte $\times$ nível de polpa cítrica sobre o $\mathrm{pH}$, sendo que ambos apresentaram resposta quadrática para esta variável. Os valores obtidos nesta pesquisa corroboram os observados por Faria et al. (1972), em experimento com silagem de capim-elefante Napier aditivada com polpa cítrica $(5,10,15$ ou $20 \%$ ), no qual a adição de polpa seca só não alterou significativamente o $\mathrm{pH}$ quando se utilizou quantidade correspondente a $5 \%$ do peso do capim. Nos outros níveis, observou-se significativa e tendência de diminuição, com a inclusão de polpa desidratada na silagem. Evangelista et al. (2001), por sua vez, não observaram efeito da adição de farelo de trigo ou da polpa cítrica $(0,5,10$ ou $15 \%)$ quando adicionados ao capim coastcross colhido com sete semanas de rebrota.

Observou-se interação idade de corte do capim $\times$ nível de inclusão de polpa cítrica sobre a concentração de nitrogênio amoniacal (\% do nitrogênio total), sendo linear para idade do capim e quadrática para o nível de polpa cítrica. Os resultados obtidos neste experimento são semelhantes aos obtidos por Bernardino et al. (2005), mas diferem dos encontrados por Rodrigues et al. (2005), que mostraram que a adição de polpa diminuiu linearmente os valores de $\mathrm{N}_{-} \mathrm{NH}_{3}$, provavelmente devido à baixa proteólise oriunda da atividade das enzimas da planta, visto que grande parte das enzimas vegetais que desintegram proteína da forragem no interior do silo são ativas somente em $\mathrm{pH}$ acima de 5,0. Braga et al. (2001) também revelaram que as concentrações de $\mathrm{N}-\mathrm{NH}_{3}$ foram significativamente afetadas pelas idades de corte, apresentando comportamento quadrático, em que o menor valor foi encontrado para o capim cortado aos 112 dias de crescimento.

Houve efeito da interação idade de corte $\times$ nível de polpa cítrica sobre as perdas de MS, sendo que a idade de corte causou resposta linear e o nível de polpa cítrica, resposta quadrática. As perdas de MS foram mais intensas com o decréscimo dos teores de MS do capim. Aguiar at al. (2000), em experimento com polpa cítrica $(0,5$ ou $10 \%)$ como aditivo em silagens de capim-tanzânia, observaram redução nas perdas por gás em níveis de adição de polpa acima de $4,25 \%$. Diferentemente dos resultados obtidos neste experimento, Rodrigues et al. (2005), trabalhando com níveis crescentes de polpa cítrica em silagem de capim-elefante, notaram maiores perdas de MS à medida que se elevou o nível de inclusão do aditivo na silagem. Segundo esses autores, o aumento da disponibilidade de CHO para os microrganismos, com a inclusão da polpa cítrica, foi possivelmente o fator que proporcionou as maiores perdas.

Os fatores estudados, idade de corte e nível de polpa cítrica, interagiram em relação à variável temperatura máxima (Temp $\left.{ }^{\circ} \mathrm{Max}\right)$. A idade de corte causou resposta quadrática e o nível de polpa, resposta linear, elevando a temperatura máxima com o aumento do nível de polpa cítrica, que foi maior com o incremento do teor de MS do capim (Tabela 4).

A idade de corte e o nível de polpa cítrica não influenciaram o tempo para atingir a temperatura máxima (TempoT $\left.{ }^{\circ} \mathrm{Max}\right)$ neste experimento. Para a taxa para elevação da temperatura (Taxa), porém, não houve efeito da interação idade de corte $\times$ nível de polpa cítrica, sendo que a idade de corte causou resposta quadrática e o nível de polpa, resposta linear, elevando a taxa de elevação da temperatura com o aumento no nível de polpa. Finalmente, para o tempo para elevação da temperatura em $2^{\circ} \mathrm{C}$ (Tempo $2^{\circ} \mathrm{C}$ ), houve somente efeito linear para a idade de corte, aumentando o tempo para elevação da temperatura com o incremento do teor de MS do capim. Este aumento no tempo parece estar relacionado à queda nos teores de carboidratos solúveis conforme o avanço do estádio vegetativo da forragem.

O aumento da temperatura máxima alcançada e da taxa de elevação da temperatura, observado com a adição da polpa cítrica, é compatível com os resultados de Rodrigues et al. (2004), que estudaram o uso de inoculante microbiano e adição de polpa cítrica em silagem de alfafa. Igarasi (2002) verificou efeito significativo do teor de MS sobre a temperatura acumulada, observando-se o maior valor no tratamento contendo polpa cítrica. 
Tabela 4 - Estabilidade aeróbia das silagens ${ }^{1}$

Table 4 - Aerobic stability of silages

\begin{tabular}{|c|c|c|c|c|c|}
\hline $\begin{array}{l}\text { Corte } \\
\text { Age }\end{array}$ & $\begin{array}{l}\text { Polpa } \\
\text { Pulp }\end{array}$ & $\begin{array}{c}\operatorname{Temp}^{\circ} \operatorname{Max}^{-} \\
\text {MaxTemp }\end{array}$ & $\begin{array}{c}\text { Tempo }^{\circ} \mathrm{Max} \\
\text { PeriodMaxT }^{\circ}\end{array}$ & $\begin{array}{l}\text { Taxa } \\
\text { Rate }\end{array}$ & $\begin{array}{c}\text { Tempo } 2^{\circ} \mathrm{C} \\
\text { Period } 2{ }^{\circ} \mathrm{C}\end{array}$ \\
\hline & \multicolumn{5}{|c|}{ Combinação (Combination) } \\
\hline \multirow[t]{4}{*}{40} & 0 & 34,81 & 92,13 & 0,16 & 13,63 \\
\hline & 3 & 32,76 & 82,25 & 0,16 & 13,50 \\
\hline & 6 & 32,95 & 80,88 & 0,15 & 12,25 \\
\hline & 9 & 33,88 & 93,88 & 0,15 & 19,25 \\
\hline \multirow[t]{4}{*}{60} & 0 & 25,33 & 89,25 & 0,03 & 40,83 \\
\hline & 3 & 29,10 & 88,13 & 0,09 & 25,88 \\
\hline & 6 & 30,18 & 100,63 & 0,08 & 27,25 \\
\hline & 9 & 29,49 & 73,63 & 0,09 & 24,88 \\
\hline \multirow[t]{4}{*}{80} & 0 & 28,77 & 65,00 & 0,10 & 27,50 \\
\hline & 3 & 29,63 & 72,13 & 0,10 & 23,25 \\
\hline & 6 & 30,61 & 74,88 & 0,12 & 33,25 \\
\hline & 9 & 34,62 & 82,75 & 0,13 & 29,38 \\
\hline \multirow[t]{4}{*}{100} & 0 & 25,62 & 67,25 & 0,05 & 26,67 \\
\hline & 3 & 28,68 & 87,38 & 0,07 & 31,13 \\
\hline & 6 & 32,24 & 75,88 & 0,12 & 25,88 \\
\hline & 9 & 30,35 & 79,88 & 0,09 & 38,38 \\
\hline \multirow[t]{4}{*}{120} & 0 & 30,16 & 82,75 & 0,09 & 32,63 \\
\hline & 3 & 28,18 & 98,13 & 0,06 & 30,33 \\
\hline & 6 & 33,27 & 70,13 & 0,14 & 31,63 \\
\hline & 9 & 30,04 & 82,38 & 0,09 & 38,38 \\
\hline Média & & 30,53 & 81,96 & 0,10 & 27,08 \\
\hline \multicolumn{6}{|l|}{ Mean } \\
\hline $\mathrm{CV}$ & & 13,27 & 39,00 & 48,08 & 50,64 \\
\hline
\end{tabular}

Probabilidade estatística (Statistical probability)

\begin{tabular}{|c|c|c|c|c|}
\hline \multicolumn{5}{|l|}{ Corte (Age) } \\
\hline Linear (L) & 0,0475 & NS & 0,0005 & 0,0006 \\
\hline Quadrática (Q) & 0,0134 & NS & 0,0015 & NS \\
\hline \multicolumn{5}{|l|}{ Polpa (Pulp) } \\
\hline Linear (L) & 0,0049 & NS & 0,0165 & NS \\
\hline Quadrática (Q) & NS & NS & NS & NS \\
\hline \multicolumn{5}{|c|}{ Interação (Interaction) } \\
\hline Corte $_{\mathrm{L}} \times$ Polpa $_{\mathrm{L}}$ & NS & NS & NS & NS \\
\hline Corte $_{\mathrm{L}} \times$ Polpa $_{\mathrm{Q}}$ & NS & NS & NS & NS \\
\hline Corte $_{\mathrm{Q}} \times$ Polpa $_{\mathrm{L}}$ & 0,0351 & NS & NS & NS \\
\hline Corte $_{\mathrm{Q}} \times$ Polpa $_{\mathrm{Q}}$ & NS & NS & NS & NS \\
\hline
\end{tabular}

${ }^{1}$ Tempo Max: temperatura máxima $\left({ }^{\circ} \mathrm{C}\right) ;$ TempoT'Max: tempo para atingir a temperatura máxima (horas); Taxa: taxa para elevação da temperatura $\left({ }^{\circ} \mathrm{C} /\right.$ hora); Tempo $2^{\circ} \mathrm{C}$ : tempo para elevação da temperatura em $2^{\circ} \mathrm{C}$ (horas); CV: coeficiente de variação (\%); NS: não-significativo.

${ }^{1}$ MaxTemp ${ }^{\circ}$ : maximum temperature $\left({ }^{\circ} \mathrm{C}\right)$; PeriodMax $T^{\circ}$ : period of time to reach maximum temperature (hours); Rate: rate for increasing temperature $\left({ }^{\circ} \mathrm{C} /\right.$ hour); Period $2{ }^{\circ} \mathrm{C}$ : period of time to increase temperature in $2^{\circ} \mathrm{C}$ (hours); CV: coefficient of variation (\%); NS: not significant.

\section{Conclusões}

Considerando-se as condições deste experimento, recomenda-se a inclusão de $0,7 \%$ de polpa cítrica peletizada para cada unidade percentual de MS que o capim possuir abaixo de $32 \%$. Estudos no campo devem ser executados a fim de validar esta recomendação. Um fator importante a se destacar neste procedimento é o cuidado com o manejo da silagem após a abertura do silo, pois, por apresentar um produto final de melhor qualidade, pode ser mais susceptível à degradação aeróbia. A inclusão de polpa cítrica peletizada em silagem de capim-elefante é indicada para melhorar a qualidade de fermentação e o valor nutritivo.

\section{Agradecimento}

Aos funcionários Everson Lázaro e Gilmar Botteon, pelo cuidado com a cultura, e aos técnicos Ari de Castro, Gilson de Godoy e Simi Aflalo, pela ajuda com as análises laboratoriais.

\section{Literatura Citada}

AGUIAR, R.N.S.; CRESTANA, R.F.; BALSALOBRE, M.A.A. et al. Avaliação das perdas de matéria seca em silagens de capim Tanzânia. In: REUNIÃO ANUAL DA SOCIEDADE BRASILEIRA DE ZOOTECNIA, 37., 2000, Viçosa, MG. Anais... Viçosa, MG: Sociedade Brasileira de Zootecnia, 2000. (CD-ROM).

ANDRADE, J.B. Produção de feno. Nova Odessa: Instituto de Zootecnia, 1999. 34p (Boletim Técnico, 44).

ASSOCIATION OF OFFICIAL ANALYTICAL CHEMISTS - AOAC. Official methods of analysis. 10.ed. Washington: 1980. $1015 \mathrm{p}$.

BERNARDINO, F.S.; GARCIA, R.; ROCHA, F.C. et al. Produção e características do efluente e composição bromatológica da silagem de capim-elefante contendo diferentes níveis de casca de café. Revista Brasileira de Zootecnia, v.34, n.6, p.21852191, 2005 (supl.).

BRAGA, A.P.; RIBEIRO, H.U.; BARRA, S.B. et al. Composição químico-bromatológica das silagens de capim-elefante cv. Cameron, em cinco idades de corte. Caatinga, v.14, n.1/2, p.17-23, 2001.

CAMPOS, F.P.; LANNA, D.P.D.; BOSE, M.L.V. Degradabilidade do capim-elefante em diferentes estágios de maturidade avaliada pelo método in vitro/gás. Scientia Agrícola, v.59, n.2, p.217$225,2002$.

CRESTANA, R.F.; AGUIAR, R.N.S.; BALSALOBRE, M.A.A. et al. Efeito da fermentação na fração fibra de silagens de capim Tanzânia. In: REUNIÃO ANUAL DA SOCIEDADE BRASILEIRA DE ZOOTECNIA, 38., 2001, Piracicaba. Anais... Piracicaba: Sociedade Brasileira de Zootecnia, 2001. (CD-ROM).

DESCHAMPS, F.C. Implicações do período de crescimento na composição química e digestão dos tecidos de cultivares de capim-elefante (Pennisetum purpureum Schum.). Revista Brasileira de Zootecnia, v.28, n.6, p.1358-1369, 1999.

ERWIN, E.S.; MARCO, G.J.; EMERY, E.M. Volatile fatty acid analyses of blood and rumen fluid by gas chromatography. Journal of Dairy Science, v.44, n.9, p.1768-1771, 1961.

EVANGELISTA, A.R.; LIMA, J.A.; BERNARDES, T.F. Avaliação de algumas características da silagem de gramínea estrela roxa (Cynodon nlemfuensis Vanderyst). Revista Brasileira de Zootecnia, v.29, n.4, p.941-946, 2000.

EVANGELISTA, A.R.; LIMA, J.A.; SIQUEIRA, G.R. et al. Aditivos na ensilagem de coast cross (Cynodon dactylon (L.) Pers.). 1. Farelo de trigo e polpa cítrica. In: REUNIÃO ANUAL DA SOCIEDADE BRASILEIRA DE ZOOTECNIA. 38., 2001, Piracicaba. Anais... Piracicaba: Sociedade Brasileira de Zootecnia, 2001. (CD-ROM).

FARIA, V.P.; TOSI, H.; GODOY, C.R.M. Polpa de laranja seca e fresca como aditivos para ensilagem de capim-elefante Napier. O Solo, v.64, n.1, p.41-46, 1972.

FERRARI JR., E.; LAVEZZO, W. Qualidade da silagem de capimelefante (Pennisetum purpureum Schum.) emurchecido ou 
acrescido de farelo de mandioca. Revista Brasileira de Zootecnia, v.30, n.5, p.1424-1431, 2001.

FOLDAGER, J. Protein requirement and non protein nitrogen for high producing cow in early lactation. East Lansing: Michigan State University, 1977. 167p. Ph.D. (Thesis in Animal Science) - Michigan State University, 1977.

HENDRIX, D.L. Rapid extraction and analysis of nonstructural carbohydrates in plant tissues. Crop Science, v.33, n.6, p.1306$1311,1993$.

HEINRICHS, J.; KONONOFF, P. Evaluating particle size of forages and TMRs using the New Penn State forage particle separator. Pennsylvania: The Pennsylvania State University/Department of Dairy and Animal Science, 2002. 14p (Technical Repost DAS 02-42).

IGARASI, M.S. Controle de perdas na ensilagem de capim Tanzânia (Panicum maximum Jacq. cv. Tanzânia) sob os efeitos do teor de matéria seca, do tamanho da partícula, da estação do ano e da presença do inoculante bacteriano. Piracicaba: Escola Superior de Agricultura "Luiz de Queiroz", 2002. 151p. Dissertação (Mestrado em Ciência Animal e Pastagens) - Escola Superior de Agricultura "Luiz de Queiroz", 2002.

JOHNSON, R.R.; BALWANI, T.L.; JOHNSON, L.J. et al. Corn plant maturity. II. Effect on in vitro cellulose digestibility and soluble carabohydrate content. Journal of Animal Science, v.25, n.3, p.617-623, 1966.

KUNG JR., L.; RANJIT, N.K. The effect of Lactobacillus buchneri and other additives on the fermentation and aerobic stability of barley silage. Journal of Dairy Science, v.84, n.5, p.1149$1155,2001$.

LAMMERS, B.P.; BUCKMASSTER, D.R.; HEINRICHS, E.J. A simple method for the analysis of particle sizes of forages and total mixed rations. Journal of Dairy Science, v.79, n.5, p.922-928, 1996.

MAHANNA, B. [1997]. Troubleshooting silage problems. Disponível em: 〈http://www.pionner.com/xweb>. Acesso em: Acesso em: 19/5/2005.

PEREIRA, J.R.A.; ROSSI JR., P. Manual prático de avaliação nutricional de alimentos. 1.ed. Piracicaba: Fundação de Estudos Agrários Luiz de Queiroz, 1995. 25p.

PERES, J.R. Avaliação da polpa de citros seca e peletizada como aditivo na ensilagem do capim elefante (Pennisetum purpureum, Schum). Piracicaba: Escola Superior de Agricultura "Luiz de Queiroz", 1997. 82p. Dissertação (Mestrado em Ciência Animal e Pastagens) - Escola Superior de Agricultura "Luiz de Queiroz", 1997.

PLAYNE, M.J.; McDONALD, P. The buffering constituints of forage. Journal of Science Food Agricuture, v.17, n.2, p.264-268, 1966.
QUEIROZ FILHO, J.L.; SILVA, D.V.; NASCIMENTO, I.S. Produção de matéria seca e qualidade do capim-elefante (Pennisetum purpureum Schum.) cultivar Roxo em diferentes idades de corte. Revista Brasileira de Zootecnia, v.29, n.1, p.69-74, 2000.

REIS, R.A.; COAN, R.M.; PEREIRA, M.S. et al. Valor nutritivo do capim Tifton 85 ensilado com diferentes conteúdos de umidade. In: REUNIÃO ANUAL DA SOCIEDADE BRASILEIRA DE ZOOTECNIA, 40., 2003, Santa Maria. Anais... Santa Maria: Sociedade Brasileira de Zootecnia, 2003. (CD-ROM).

RODRIGUES, P.H.M.; ALMEIDA, L.F.S.; LUCCI, C.S. et al. Efeito da adição de inoculantes microbianos sobre o perfil fermentativo da silagem de alfafa adicionada de polpa cítrica. Revista Brasileira de Zootecnia, v.33, n.6, p.1646-1653, 2004.

RODRIGUES, P.H.M.; BORGATTI, L.M.O.; SOUZA, R.W. et al. Níveis crescentes de polpa cítrica sobre a qualidade fermentativa da silagem de capim-elefante. Revista Brasileira de Zootecnia, v.34, n.4, p.1138-1145, 2005.

RUPPEL, K.A.; PITT, R.E.; CHASE, L.E. et al. Bunker silo management and its relationship to forage preservation on dairy farms. Journal of Dairy Science, v.78, n.1, p.141-153, 1995.

STATISTICAL ANALYSIS SYSTEM - SAS. User's guide: statistics. 5.ed.rev. Cary: 1985. 441p.

SILVA, J.C.; LEÃO, M.I. Fundamentos de nutrição de ruminantes. Piracicaba: Livroceres, 1979. p.190-236.

SILVEIRA, A.C.; LAVEZZO, W.; SILVEIRA FILHO, S. et al. Consumo de silagem de capim-elefante (Pennisetum purpureum, Schum) submetidas a diferentes tratamentos. Revista Brasileira de Zootecnia, v.9, n.2, p.306-320, 1980.

TILLEY, J.M.A.; TERRY, R.A. A two-stage technique for the in vitro digestion of forage crops. The Journal of the British Grassland Society, v.18, n.2, p.104-111, 1963.

Van SOEST, P.J.; ROBERTSON, J.B. Analysis of forages and fibrous foods. Ithaca: Cornell University, 1985. 202p.

Van SOEST, P.J.; ROBERTSON, J.B.; LEWIS, B.A. Symposium: Carbohydrate methodology, metabolism, and nutritional implications in dairy cattle. Methods for dietary fiber, neutral detergent fiber, and nonstarch polysaccharides in relation to animal nutrition. Journal of Dairy Science, v.74, n.1, p.35833597, 1991.

VILELA, H. [2004]. Silagem de gramínea (capim) tropical. Disponível em: <http:www.zootecnia.com.Br/forragicultura/ silagemdegramínea.html>. Acesso em: Acesso em: 19/5/2005. 